\author{
Military Technical College \\ Kobry El-Kobbah, \\ Cairo, Egypt.
}

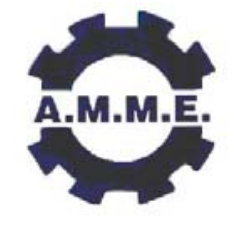

$13^{\text {th }}$ International Conference on Applied Mechanics and Mechanical Engineering.

\title{
EXPERIMENTAL AND NUMERICAL INVESTIGATIONS OF FORCED CONVECTION OVER AN INCLINED HEATED FLAT PLATE
}

\author{
FAYEK* M.A., GOMAA** A.G., MOAWED* M.A., El-HENDAL* Y.A.
}

\begin{abstract}
This work presents the considerations and results of thermofluid characteristics of air flow over an inclined heated flat plate with particular reference to solar collector. The study is motivated by the need to better understanding of heat transfer from the top surface of flat-plate solar energy collectors. The effects of angle of attack, heat flux and Reynolds number are experimentally and numerically investigated. The plate was fixed in the test section with a special mechanism have a capability of changing the angle of attack. A finite volume descretization method using body-fitted coordinates and SIMPLE-based solution algorithm are applied with a segregated solver. The momentum and energy equations were solved by the second order upwind scheme. The fluid flow and heat transfer over the inclined flat plate are treated using $k-\varepsilon$ RNG turbulent model. The model results are validated with the experimental results at the same particular conditions. The validated CFD model was extended to obtain the performance of a wide range of angle of attack and flow rate. The local distributions of the velocity, pressure and turbulence with different angle of attack are presented.
\end{abstract}

\section{KEY WORDS}

Solar collector, forced convection, Flat plate, angle of attack, CFD

* Faculty of Engineering, Banha University, Cairo, Egypt.

** Faculty of Industrial Education, Helwan University, Cairo, Egypt. 


\section{NOMENCLATURE}

\section{Symbol Description}

$A_{s} \quad$ Plate surface area

Cp Specific heat,

$f \quad$ Friction factor, dimensionless

$h \quad$ Heat transfer coefficient

grad $\quad$ Gradient $(\operatorname{grad} u=\partial \mathrm{u} / \partial \mathrm{x}+\partial \mathrm{u} / \partial \mathrm{y}+\partial \mathrm{u} / \partial \mathrm{z})$

$k \quad$ Thermal conductivity

$L \quad$ Flat plate Length

$\mathrm{Nu} \quad$ Nusselt number, $h D / k$, dimensionless

$\operatorname{Pr} \quad$ Prandtl number, dimensionless

$\Delta p \quad$ Pressure drop

$\mathrm{Re} \quad$ Reynolds number, dimensionless

u Velocity vector, $\left(u_{i+} v_{j+} w_{k}\right)$

$u \quad$ Air velocity

$T \quad$ Temperature

\section{Greek letters}

$\alpha \quad$ Angle of attack

$\mu \quad$ Viscosity

$\rho \quad$ Density

\section{Subscripts}

$\begin{array}{clcl}a & \text { Air } & \mathrm{i} & \text { Inlet } \\ a v & \text { Average } & \mathrm{o} & \text { outlet } \\ \max & \text { Maximum } & \mathrm{w} & \text { wall }\end{array}$

Unit

$m^{2}$

$\mathrm{J} / \mathrm{kg} \mathrm{K}$

$W / m^{2} K$

$W / m K$

m

$N / m^{2}$

$\mathrm{m} / \mathrm{s}$

$\mathrm{m} / \mathrm{s}$

${ }^{\circ} \mathrm{C}$

degree

$\mathrm{Ns} / \mathrm{m}^{2}$

$\mathrm{kg} / \mathrm{m}^{3}$

\section{INTRODUCTION}

Forced convection heat transfer from a flat plate has been a topic of important fundamental and engineering interests during the past decades. The study of forced convection from flat plate has gained considerable attention because of its wide employing in many practical fields in the area of energy conservation, design of solar collectors, cooling of electrical and electronic equipments and many others.

The review of the previous studies is summarized in two categories, the first one discussed the steady state condition and the second one discussed the transient condition. The forced convection heat transfer from an inclined square plate was investigated by Sparrow et al [1]. Heat transfer coefficients measured in those experiments were found to be intensive to the angle of attack for a wide range of angles. Also, the effect of finite width on heat transfer and fluid flow about an inclined rectangular plate was investigated by Sparrow et al [2]. These experiments showed that the dimensionless heat transfer coefficient expressed in terms of the Colburn $j$ - factor was varied with Reynolds number. Motwani et al [3] presented an experimental study to determine the heat transfer coefficient during forced convection air flow over inclined rectangular plates. The experiments were performed for constant surface temperature and covered two plates with two different aspect ratios. The results showed that the average heat transfer coefficient was a function of the Reynolds number and the angle 
of attack but it was insensitive to the aspect ratio. Shalaby et al [4] carried out an experimental investigation to determine the heat transfer coefficient by forced convection from a flat plate held in air stream. The plate was carried out at varies angles of attack. He concluded that the angle of attack has a relatively small effect on the heat transfer coefficient but the heat transfer coefficient was significantly affected by the angle of yaw. Reda [5] investigate experimentally the heat transfer to air flowing over an inclined flat plate. A flat plate of $320 \mathrm{~mm}$ length and $120 \mathrm{~mm}$ width made of brass was taken as a heating surface. The experiments were performed at a relatively low range of $\operatorname{Re}$ from $0.3 * 10^{5}$ to $2.5^{*} 10^{5}$ and the angle of attack was varied from 0 to 30 degree. The results showed that the heat transfer coefficient increases with the angle of attack and it reaches a maximum value at an angle of 20 degree then it begins to decrease with further inclination of plate. Vynnycky et al [6] studied analytically and numerically the Forced convection heat transfer from a flat plate. Both internal and external thermal conductivities are taken into consideration by means of a conjugate model consisting of the full Navier- Stokes equations for the fluid medium and the energy equations for both the fluid and the slab. The analysis facilitates the investigation of the effects of the Reynolds number (Re), the Prandtl number (Pr), the thermal conductivity ratio $(k)$ between the slab and the fluid medium and the slab aspect ratio (2) on the heat transfer characteristics. For $\operatorname{Re}>>1$, boundary-layer theory is used to derive two methods of solution whose results are compared with the full numerical solutions. Giulio Lorenzini [7] studied an experimental analysis of the air flow field over a hot flat plate. A light coil as a partial tracer of the air flow field was used. The study measures the variation of the angular velocity of the coil with variations in the temperature of the hot plate beneath and other influencing parameters related to the geometry of the tracer. Ernani [8] developed correlations of convection coefficient for forced air flow over flat surfaces. The forced convection heat transfer coefficient for flat surfaces or particularly for flat plate solar collectors has mainly been calculated through well known empirical equations. These equations are compared with those that come from the boundary layer theory with the aim at detecting corresponding accuracies and validations, and trying to find a consensus on which of them is more exact for the calculation of the heat transfer coefficient by forced convection over plane surfaces, and particularly over flat plate solar collectors.

Butler and Baughn, [9] presents the effect of the thermal boundary conditions on transient method heat transfer measurements on a flat plate with a laminar boundary layer. The heat transfer coefficient to transient regimes as well and all the experimental evaluations of this coefficient with transient methods rely on the assumption that heat transfer coefficient is not influenced by the temperature unsteadiness, despite of the existing experimental and theoretical evidence that in transient methods the heat transfer coefficient varies with time (Harris et al [10] and Lachi et al [11]). Cossali [12] studied the Periodic heat transfer by forced laminar boundary layer flow over a semiinfinite flat plate. The effect of periodic heating on the value of the average heat transfer coefficient is analyzed and it is found to be important for relatively high frequency fluctuations of the imposed heat flux, whereas fluctuation amplitude of the instantaneous heat transfer coefficient is non-negligible also for lower exciting frequency. Ali et al [13] presented a study on Identification models for transient heat transfer on a flat plate. The temperature profile of the plate surface is determined with an infrared camera when the plate is exposed to the controlled heat flux. Green functions are used to determine analytical solutions for the heat flux equation in the plate. These analytical solutions allow the transient convective heat transfer to be identified. 
As can be seen from the literature review, there were no enough data on experimental and numerical investigation of forced convection of air flow over an inclined flat plate. So, the present investigation has been carried out to provide a detailed study experimentally and numerically on the thermal performance of the air flow over an inclined flat plate at different angles of attack, heat flux, and Reynolds number. The prediction of general correlations of the heat transfer and friction is also concerned. The local Nusselt number on the surface of the inclined flat plate for a wide range of angle of attack is also objective.

\section{EXPERIMENTS}

The experiments are conducted in a plexiglass wind tunnel. The experimental test rig consists mainly of a square duct of $0.3 \mathrm{~m}$ by $0.3 \mathrm{~m}$ and $5 \mathrm{~m}$ length equipped with suction centrifugal fan as shown in Fig. (1). The fan has a power of $3.67 \mathrm{~kW}$ and it was linked with a variable speed inverter having a capability to fine tuning of air velocity. The average air velocity in the test section is varied from $3.8 \mathrm{~m} / \mathrm{s}$ to $20 \mathrm{~m} / \mathrm{s}$ corresponding to Reynolds number of 67000 to 367000 , respectively. A square-cells honeycomb of $0.008 \mathrm{~m} \times 0.008 \mathrm{~m} \times 0.001 \mathrm{~m}$ each is fixed at the end of the entrance section in order to smoothes and straightens the intake flow. The velocity profile of air through the duct section is identified by hotwire anemometer with a resolution of $0.1 \mathrm{~m} / \mathrm{s}$. The flat plate $\left(0.3 m{ }^{*} 0.25 m\right.$ surface area $)$ is fixed in the test section with a special mechanism have a capability of changing the angle of attack. The angle of attack have been adjusted by turning the plate around a vertical axis from $0^{\circ}$ to $40^{\circ}\left(0^{\circ}, 10^{\circ}, 20^{\circ}, 30^{\circ}, 40^{\circ}\right)$ using a protractor mechanism. The plate is heated from its down surface by electric heater. A variac is used to adjust the electrical power consumed by the heater. The other surface of the heater is covered by Insulation material to minimize the heat loss form other end of the plate as shown in Fig. (2a).

The pressure drop across the inclined plate is measured using digital micromanometer with a resolution of $1 \mathrm{~N} / \mathrm{m}^{2}$. The uncertainty in measurements of both air velocity and pressure drop are estimated that is in order of $\pm 4 \%$ and $\pm 1 \%$ of the reading respectively. The velocity and pressure measurements are carried out according to ASHRAE recommendations, [14]. Twenty one K-type thermocouple probes are fixed as log scale manner on both transverse and longitudinal axis of the plate with uncertainty of $\pm 0.5{ }^{\circ} \mathrm{C}$. The air temperature is measured on the upstream and downstream sections of the test section using three and six grid points of the K-type thermocouple probes respectively. All the thermocouples are connected via switching box to a digital thermometer with uncertainty of $\pm 0.5{ }^{\circ} \mathrm{C}$. Sufficient times are allowed to get the experiment measuring parameters stabilization, which is observed to be roughly about 40-50 minutes.

\section{NUMERICAL MODELLING}

The governing equations that describe the thermofluid characteristics from the inclined flat plate are a set of non-linear partial differential equations (PDEs). The air flow is governed by the mass, momentum and energy equations. Generally, the governing equations can be written as; [15]: 
Mass;

$$
\frac{\partial \rho}{\partial t}+\operatorname{div}(\rho \mathbf{u})=0
$$

Momentum;

$\frac{\partial(\rho u)}{\partial t}+\operatorname{div}(\rho u \mathbf{u})=-\frac{\partial p}{\partial x}+\operatorname{div}(\mu \operatorname{grad} u)+\left[-\frac{\partial\left(\overline{\rho u^{\prime 2}}\right)}{\partial x}-\frac{\partial\left(\rho \overline{u^{\prime} v^{\prime}}\right)}{\partial y}\right]$
$\frac{\partial(\rho v)}{\partial t}+\operatorname{div}(\rho v \mathbf{u})=-\frac{\partial p}{\partial y}+\operatorname{div}(\mu \operatorname{grad} v)+\left[-\frac{\partial\left(\rho \overline{u^{\prime} v^{\prime}}\right)}{\partial x}-\frac{\partial\left(\overline{\rho v^{\prime 2}}\right)}{\partial y}\right]$

\section{Energy;}

$\frac{\partial(\rho E)}{\partial t}+\operatorname{div}(\rho E \mathbf{u})=\operatorname{div}(k \operatorname{grad} T)+\left[-\frac{\partial\left(\rho \overline{u^{\prime} E^{\prime}}\right)}{\partial x}-\frac{\partial\left(\overline{\rho v^{\prime} E^{\prime}}\right)}{\partial y}\right]$

In order to solve these equations, a finite volume discretization method using a SIMPLE-based solution algorithm of the velocity-pressure coupling is applied with a segregated solver. The numerical modeling of the turbulent flow over the flat plate is solved using FLUENT-6.2.16 CFD program. The momentum and energy equations are solved by the second order upwind scheme. The thermofluid characteristics from the flat plate is treated using $k-\varepsilon$ RNG "renormalization group" turbulence model. The RNG model is more accurate and reliable for a wider class of flow than the standard $k-\varepsilon$ model, [16]. The transport equations of the RNG $k-\varepsilon$ model are given as;

$$
\begin{aligned}
& \frac{\partial}{\partial t}(\rho k)+\frac{\partial}{\partial x_{i}}\left(\rho k u_{i}\right)=\frac{\partial}{\partial x_{j}}\left(\alpha_{k} \mu_{e f f} \frac{\partial k}{\partial x_{j}}\right)+G_{k}+G_{b}-\rho \varepsilon+S_{k} \\
& \frac{\partial}{\partial t}(\rho \varepsilon)+\frac{\partial}{\partial x_{i}}\left(\rho \varepsilon u_{i}\right)=\frac{\partial}{\partial x_{j}}\left(\alpha_{\varepsilon} \mu_{e f f} \frac{\partial \varepsilon}{\partial x_{j}}\right)+C_{1 \varepsilon} \frac{\varepsilon}{k}\left(G_{k}+C_{3 \varepsilon} G_{b}\right)-C_{2 \varepsilon} \rho \frac{\varepsilon^{2}}{k}-R_{\varepsilon}+S_{k}
\end{aligned}
$$

Where; $\quad G_{k}=-\rho \overline{u_{i}^{\prime} u_{j}^{\prime}} \frac{\partial u_{j}}{\partial x_{i}}, \quad R_{\varepsilon}=\frac{C_{\mu} \rho \xi^{3}\left(1-\xi / \xi_{o}\right)}{1+\psi \xi^{3}} \frac{\varepsilon^{2}}{k}$,

$G_{b}=g_{i} \frac{\mu_{t}}{\rho P r_{t}} \frac{\partial \rho}{\partial x_{i}}, \quad C_{3 \varepsilon}=\tanh \left|\frac{v}{u}\right|, \quad S_{k}=\xi \varepsilon$

The model constants; $\mathrm{C}_{1 \varepsilon}, \mathrm{C}_{2 \varepsilon}, \alpha_{\mathrm{k}}, \alpha_{\varepsilon}, \xi_{\mathrm{o}}$ and $\psi$ in equations (5) and (6) are;

$C_{1 \varepsilon}=1.42 ; C_{2 \varepsilon}=1.68 ; \alpha_{k}=\alpha_{\varepsilon} \approx 1.393 ; \xi=4.34 ;$ and $\psi=0.012 ;[17]$

The term $G_{k}$ represents the generation of turbulence kinetic energy due to the mean velocity gradients and $G_{b}$ represents the generation of turbulence kinetic energy due to buoyancy. The quantities $\alpha_{k}$ and $\alpha_{\varepsilon}$ are the inverse of Prandtl numbers for both $k$ and $\varepsilon$ respectively.

The numerical solution transform the set of partial differential equations into a discretised algebraic form and solve them in order to obtain a set of flow field values at 
discrete points in time and space. The discrete of non-linear governing equations are linearised to produce a system of equations for the dependent variables in every computational cell. The resultant linear system is then solved to yield an updated flowfield solution. For a given variable, the unknown value in each cell is computed using a relation that includes both existing and unknown values from neighboring cells. Therefore each unknown will appear in more than one equation in the system, and these equations must be solved simultaneously to give the unknown quantities. The computational domain is discretised into a set of control volumes, which are arranged into a grid.

The governing equations can be expressed in a general form of a general variable, $\varphi$ as:

$$
\frac{\partial(\rho \varphi)}{\partial t}+\operatorname{div}(\rho \varphi \mathbf{u})=\operatorname{div}(\Gamma \operatorname{grad} \varphi)+S_{\varphi}
$$

where $\partial(\rho \varphi) / \partial t$ is the rate of change of variable $\varphi, \operatorname{div}(\rho \varphi \mathbf{u})$ is the convective term, $\operatorname{div}(\Gamma \operatorname{grad} \varphi)$ is the diffusive term and $S_{\varphi}$ is source term. This general equation can describe the continuity, momentum and energy of the air flow by setting the general variable $\varphi$ equal to $1,(u, v, w)$ and $T$ respectively. This equation is used as the starting point for the computational procedures. Discretization of the governing equations can be illustrated by considering integration on a control-volume of the general equation (7):

$$
\int_{C V} \frac{\partial(\rho \varphi)}{\partial t}+\int_{C V} \operatorname{div}(\rho \varphi \mathbf{u})=\int_{C V} \operatorname{div}(\Gamma \operatorname{grad} \varphi)+\int_{C V} S_{\varphi}
$$

Equation (8) is applied to each cell in the domain which yields algebraic equation on a given cell;

$$
\sum_{f}^{N_{\text {faces }}} \mathrm{u}_{f} \varphi_{f} A_{f}=\sum_{f}^{N_{\text {faces }}} \Gamma_{\varphi}(\operatorname{div} \varphi)_{n} A_{f}+S_{\varphi} V
$$

Preliminary simulation was carried out with different grid numbers in order to get a gridindependent solution. Considering both accuracy and economics, the computations were performed with grid-cell size of $0.1 \mathrm{~mm}$ as shown in Fig. (2-b). Solution with adaptive-grid refinement of a hanging nodes technique is adopted to increase grid density based on the evolving flow field, and thus provides the potential for more economical use of grid points. The convergence criterion for all runs is specified to less than $10^{-4}$.

\section{BOUNDARY CONDITIONS}

The numerical solution of the turbulent flow over the inclined flat plate is treated as steady, incompressible, two dimensional with neglecting the buoyancy force. At the upstream boundary that located three times of the flat plate length, a uniform flow velocity is specified. At the downstream boundary that located six times of the flat plate length, the pressure is site to zero. While at the solid surfaces, no-slip conditions and constant wall heat flux are specified 


\section{DATA REDUCTION}

The heat transfer coefficient of the numerical model is given as:

$$
h_{a}=\frac{\dot{m}_{a} C p_{a}\left(T_{a o}-T_{a i}\right)}{A_{s} \theta}, \quad \theta=\frac{\left(T_{w i}-T_{a i}\right)-\left(T_{w o}-T_{a o}\right)}{\ln \left(\left(T_{w i}-T_{a i}\right) /\left(T_{w o}-T_{a o}\right)\right)}
$$

The Nusselt number is defined as;

$$
N u=\frac{\rho u L}{\mu}
$$

Another quantity characterizing the flow across the inclined plate is the friction factor;

$$
f=\frac{2 \Delta P}{\rho u^{2}}
$$

The temperature and the pressure at any section of the model can be computed numerically as;

$$
T=\frac{\int T \rho \overrightarrow{\mathbf{u}} \cdot d \vec{A}}{\int \rho \overrightarrow{\mathbf{u}} \cdot d \vec{A}}, \quad p=\frac{\int p \rho \overrightarrow{\mathbf{u}} \cdot d \vec{A}}{\int \rho \overrightarrow{\mathbf{u}} \cdot d \vec{A}}
$$

\section{RESULTS AND DISCUSSION}

The experimental and numerical works of this study are performed to study the effects of Reynolds number, heat fluxes, and angles of attack of the flow stream with respect to the flat plate on the fluid flow and heat transfer characteristics from the heated flat plate in cross flow.

Figure 3, shows an experimental sample of the variation of average Nusselt number with the Reynolds number of the heated flat plat for the different angles of attack $(\alpha=$ $10,20,30$ and $40^{\circ}$ ). This figure illustrates that Nusselt number Nusselt number is increased with $\mathrm{Re}$ for all cases but the Nusselt number changed dramatically with angle of attack. The $\mathrm{Nu}$ is increased from $\alpha=10^{\circ}$ to $\alpha=20^{\circ}$ but it decreased at $\alpha=30^{\circ}$ and $40^{\circ}$ less than that at $\alpha=20^{\circ}$. This result is conformed that the previous work of Ref. [5]. This can be explained as the following, at small angle of attack $\left(\alpha \leq 20^{\circ}\right)$ the stream of air flow become more impact with the heated flat plate where there is no or small stagnation zoon of air at the lower edge in front of the plate, but at large angle of attack $\left(\alpha \geq 20^{\circ}\right)$ the stagnation zoon of air in front of air in front of the plate is increased which lead to decrease in heat transfer coefficient. 
The numerical results of the Nusselt number and friction factor were validated with the corresponding experimental results and with also previously published work as illustrated in Fig. 4 and Fig. 5 respectively. This figures shows that a fair agreement between the present experimental and numerical results at different angles of attack and also with that of Ref. [5]. Figure 6 shows the variation of average Nusselt number with Reynolds number at different angles of attack based on numerical results. This figure indicate that, the maximum value of Nusselt number is achieved at $\alpha=20^{\circ}$

Local Nusselt number on the surface of the inclined flat plate for a wide range of angle of attack is the objective of the present work. Figure 7 shows the variation of local Nusselt number $\left(\mathrm{Nu}_{\mathrm{x}}\right)$ with local distance $\mathrm{x} / \mathrm{L}$. The maximum value of Nusselt number is obtained at $x / L=0$ while the minimum valued is observed at $x / L=1$.

The effect of angle of attack ( $\alpha$ ) on the friction factor (f) vs. Reynolds number is shown in Fig. 8. This figure shows that the friction factor ( $f$ ) decreases with the increase of Reynolds number while it increases with the increase of angle of attack. The angle of attack affect the pressure drop positively due it is obstacle to the stream of air flow causing more flow resistance. Figure 9 shows the variation of Nusselt number with $\alpha$ at different Reynolds number. At the same angle of attack, the Nusselt number increases with the increase of Reynolds number. For all angles of attack, the Nusselt number is increased from $\alpha=0^{\circ}$ to $\alpha=20^{\circ}$ and then it begins to decrease.

The effect of heat flux on the Nusselt number is illustrated in Fig. 10. This figure shows that, at different values of heat fluxes the change in Nusselt number are small which mean that there is no a significant influence effect of heat flux on the Nusselt number.

The air flow pattern contours $(u=16 \mathrm{~m} / \mathrm{s})$ over the inclined flat plat for different angles of attack $\left(\alpha=20^{\circ}, 40^{\circ}, 60^{\circ}, 80^{\circ}\right)$ is illustrated in Fig. (11a-d). The flow is accelerated as the angle of attack tend to right angle which possessing a great amount of momentum. This condition increase the level of turbulence through the flow passage which enhance the heat transfer coefficient however higher pressure drop is expected.

Figures $(12 a-d)$ shows the local pressure distribution over the inclined flat plate for different angles of attack $\left(\alpha=20^{\circ}, 40^{\circ}, 60^{\circ}, 80^{\circ}\right)$. It is cleared that the angle of attack affects the pressure drop positively. For the fan power point of view, the airflow with angle of attack $=0^{\circ}$ was better than that of $\alpha>0^{\circ}$ which is characterized by a lesser flow resistance.

The level of turbulence (Turbulent kinetic energy) increases as the angle of attack increases. Fig. (13a-d) shows the turbulent kinetic energy contours for different angles of attack $\left(\alpha=20^{\circ}, 40^{\circ}, 60^{\circ}, 80^{\circ}\right)$. Higher values of the turbulent level are obtained at higher values of angle of attack and Reynolds number.

General Nusselt number and friction factor correlations are predicted for the present investigation at different angle of attack and Reynolds number with a maximum deviation of $\pm 15 \%$ and $\pm 12 \%$ respectively;

$$
\begin{aligned}
N u & =1.515 \operatorname{Re}^{0.5}(1+\sin \alpha)^{-0.446} \\
f & =0.1985 \operatorname{Re}^{-0.314}(1+\sin \alpha)^{0.352}
\end{aligned}
$$




$$
5.1 * 10^{4} \leq \operatorname{Re} \leq 7.8 * 10^{5}, \quad 0^{\circ} \leq \alpha \leq 90^{\circ}
$$

\section{CONCLUSION}

Forced convection heat transfer from a heated flat plate with different angles of attack is studied experimentally and numerically. The experiments covered a range of Reynolds number of $5.1 * 10^{4} \leq \operatorname{Re} \leq 7.8 * 10^{5}$, and $0^{\circ} \leq \alpha \leq 90^{\circ}$. Numerical CFD solution of flow field over the inclined flat plate has been also investigated. A considerable agreement between the experimental and numerical results is achieved. The average Nusselt number and friction factor are correlated with Reynolds number and angle of attack. The main conclusion of the present investigation can be summarized as:

1. The average Nusselt number increases with angle of attack ranged from $0^{\circ} \leq$ $\alpha \leq 20^{\circ}$ and then it is gradually decreases with the increase of the angle of attack.

2. Fair agreement between the present experimental and numerical results with the previously published work ( Ref. [5]).

3. The friction factor decrease with the increase flow angle of attack as well as Reynolds number.

4. Higher values of the turbulent level are obtained at higher values of both angle of attack and Reynolds number.

5. The maximum value of local Nusselt number is obtained at $x / L=0$ while the minimum value is observed at $x / L=1$.

6. There is no a significant influence effect of heat flux on both Nusselt number and friction factor.

7. On the going work the three dimensions of the thermofluid characteristics over the inclined flat plate with different aspect ratio, angle of attack, yaw angle and flow rate will be investigated in turbulent flow regime.

\section{REFERENCES}

[1] Sparrow, E.M and Tien, K.K" Forced convection heat transfer at an inclined and yawed square plate- application to solar collector" ASME, J. of Heat and Transfer , Vol 99, 1977, pp 509-512.

[2] Sparrow, E.M; Ramsey, J, W and Mass, E.A " Effect of finite width on heat transfer and fluid flow about an inclined rectangular plate" ASME, J. of Heat and Transfer, Vol 101, 1979, pp 199-204.

[3] Motwani, D.G; Gaitonde, U.N; and Sukhatme, S.P. " Heat transfer from rectangular plates inclined at different angles of a hack and yaw to an air stream" ASME, J. of Heat Transfer Vol. 107, 1985, pp. 307-312.

[4] Shalaby, M.A; Ariad, F.F; and Desoky, A.A. " Forced Convection heat transfer at an inclined and yawed rectangular plate" Bulletin of the Faculty of Eng. , ElMansoura Univ., Vol. 11, June 1986, P. M27.

[5] Reda, A. "Air flow and heat transfer characteristics over an inclined flat plate", M. Sc. Thesis, Faculty of Eng. Cairo Univ. 1989.

[6] M. Vynnycky; S. Kimura; K. Kanev and I. Pop " Forced convection heat transfer from a flat plate: the conjugate problem" Int J. Heat Mass Transfer. Vol. 41, No. I. pp. $45-59,1998$ 
[7] Giulio L., "Experimental analysis of the air flow field over a hot flat plate" International Journal of Thermal Sciences 45 (2006) 774-781

[8] Ernani S. ' Convection coefficient equations for forced air flow over flat surfaces" Solar Energy (2006)

[9] R.J. Butler, J.W. Baughn, "The effect of the thermal boundary conditions on transient method heat transfer measurements on a flat plate with a laminar boundary layer", J. Heat Transfer 118 (1996) 831-837.

[10] S.D. Harris, D.B. Ingham, and I. Pop, "Transient boundary layer heat transfer from a flat plate subjected to a sudden change in heat flux", Eur. J. Mech. BFluids 20 (2001) 187- 204.

[11] M. Lachi, M. Rebay, E. Cerna Mladin, J. Padet, "Alternative models for transient convection heat transfer in external flows over a plate exposed to a variable heat flux", Int. J. Therm. Sci. 43 (2004) 809-816.

[12] Cossali, G.E. "Periodic heat transfer by forced laminar boundary layer flow over a semi-infinite flat plate" International Journal of Heat and Mass Transfer 48 (2005) 4846-4853

[13] Ali G.; Didier S.; Jean-Yves D.; and Souad H. "Identification models for transient heat transfer on a flat plate" Experimental Thermal and Fluid Science 31 (2007) 701-710

[14] ASHRAE Handbook of Fundamentals (2001), SI edition, chapter 14, ASHRAE Inc., Atlanta, GA, USA

[15] Versteeg H. K. and Malalasesekera W 1995. An introduction to computational fluid dynamics, the finite volume method. Longman Group LTD, UK

[16] Afify R., Berbish N., Gomaa A., and Eid A., 2004, "Numerical and experimental study of turbulent flow and convective heat transfer in a circular tube with discbaffles", Engineering research journal, Vol. 96, PP M37-M61.

[17] FLUENT, 2005 user's manual, Fluent Inc., USA. 




Fig. (1) Schematic diagram of the test rig

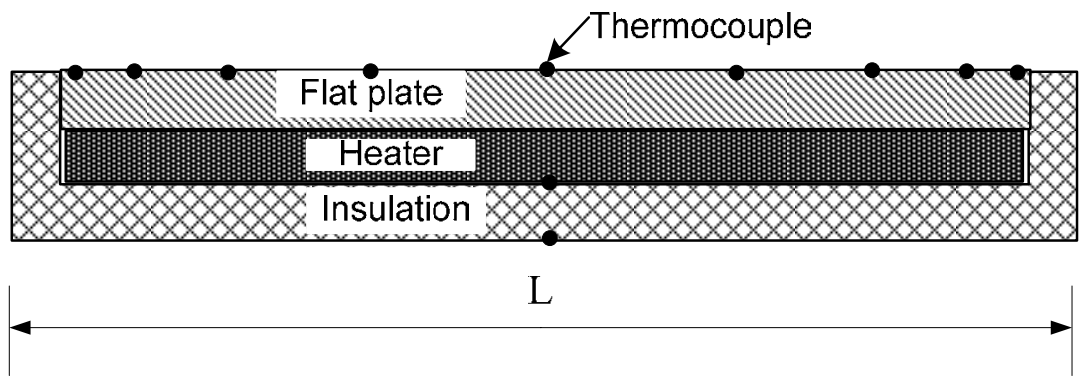

Fig. (2) Scheme of the specimen, heater and insulator assembly.

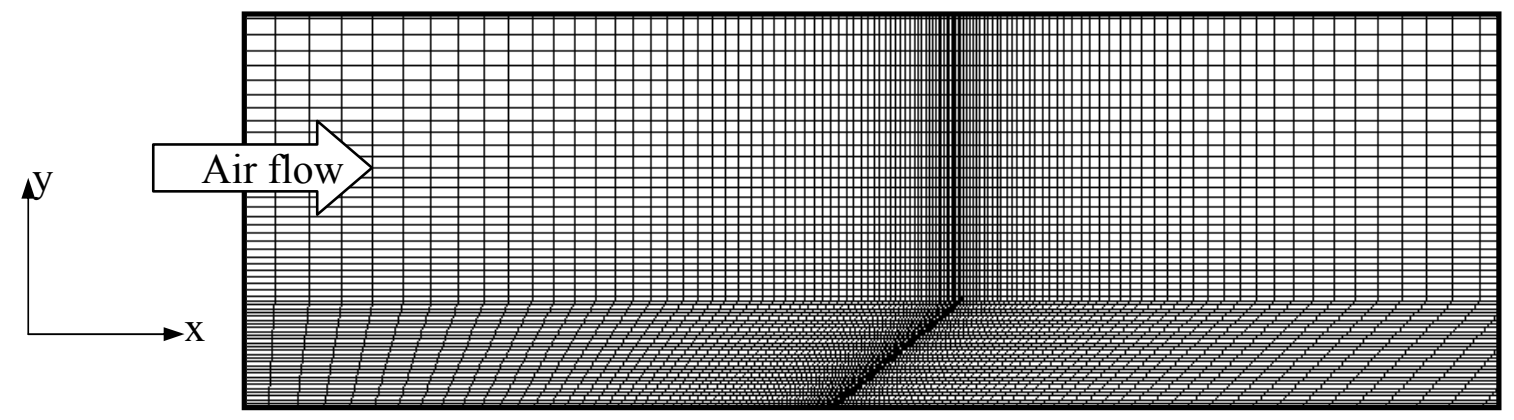

Fig. (2-b) Typical grid distribution of numerical model 


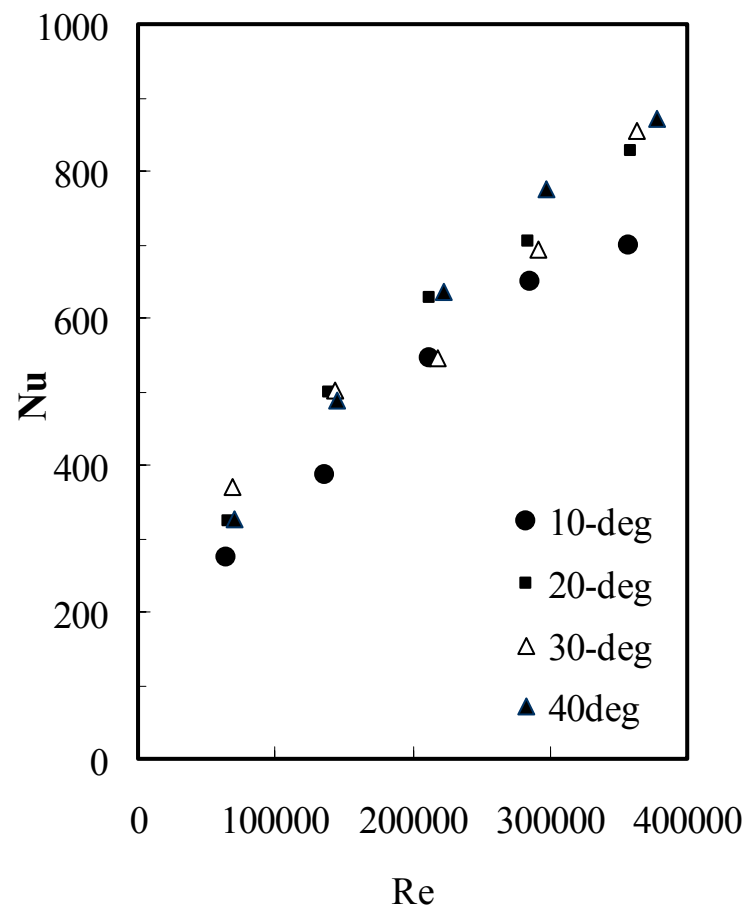

Fig. (3) Experimental result for Nusselt Number vs. Reynolds number

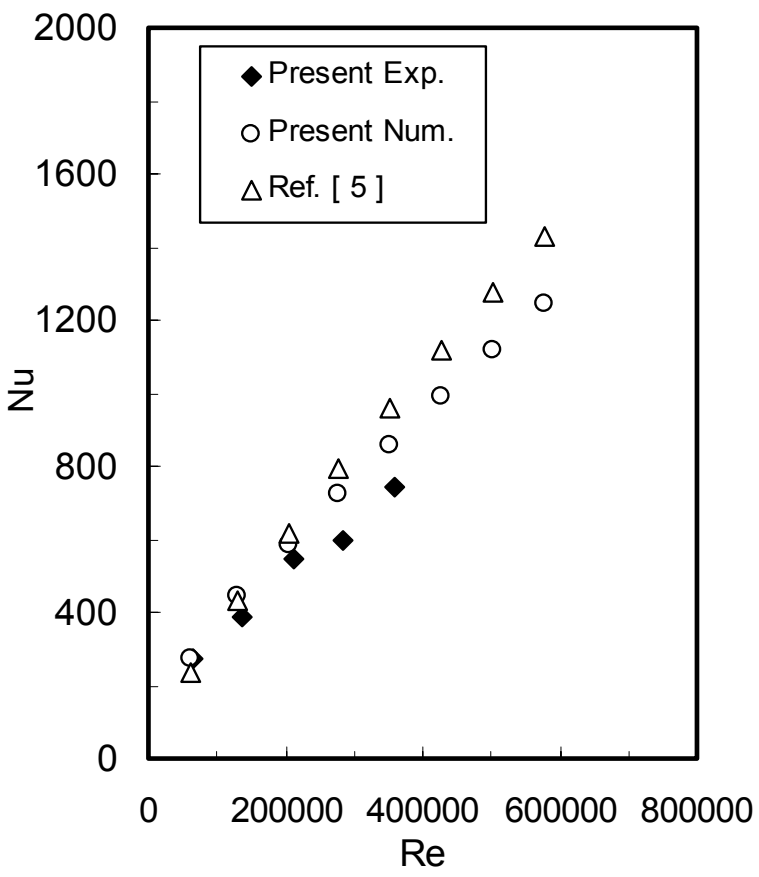

Fig. ( 5 ) Comparison between present experimental and numerical results with Ref. [5] at $\alpha=10^{\circ}$



Fig. (4) Numerical results validation of $\mathrm{Nu}$ vs. Re for different angles of attack

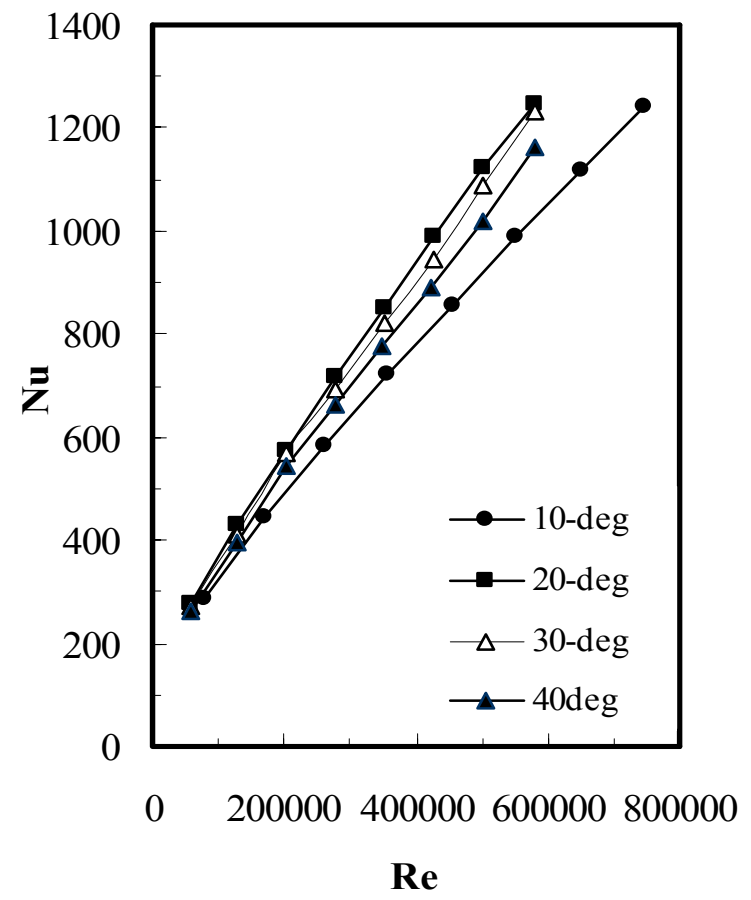

Fig. (6) Numerical results for Nusselt Number vs. Reynolds number at different angles of attack 


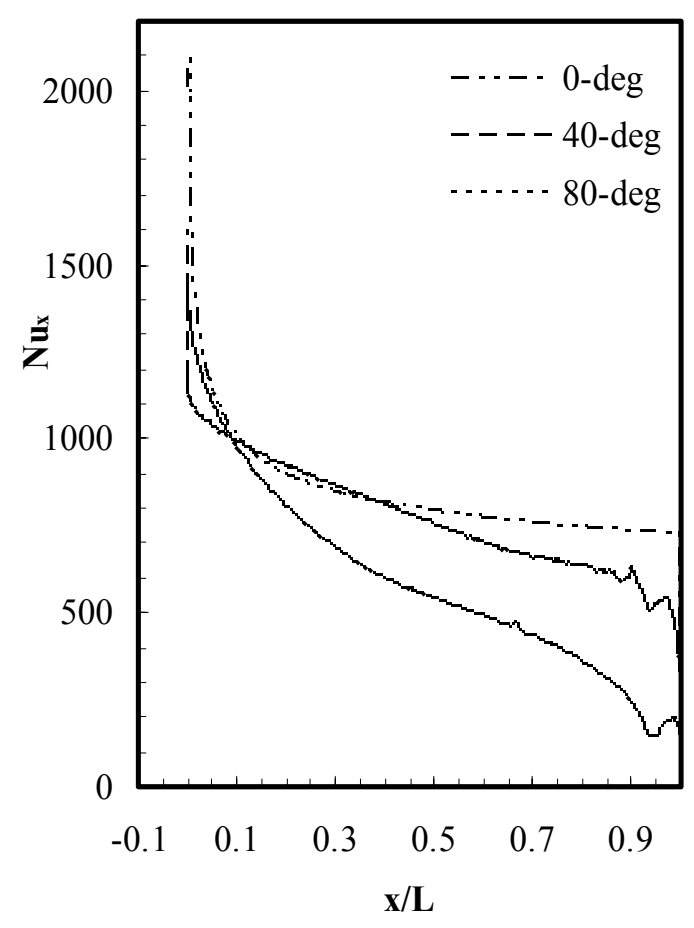

Fig. (7) Local Nusselt number vs. local distance from leading edge of the plate

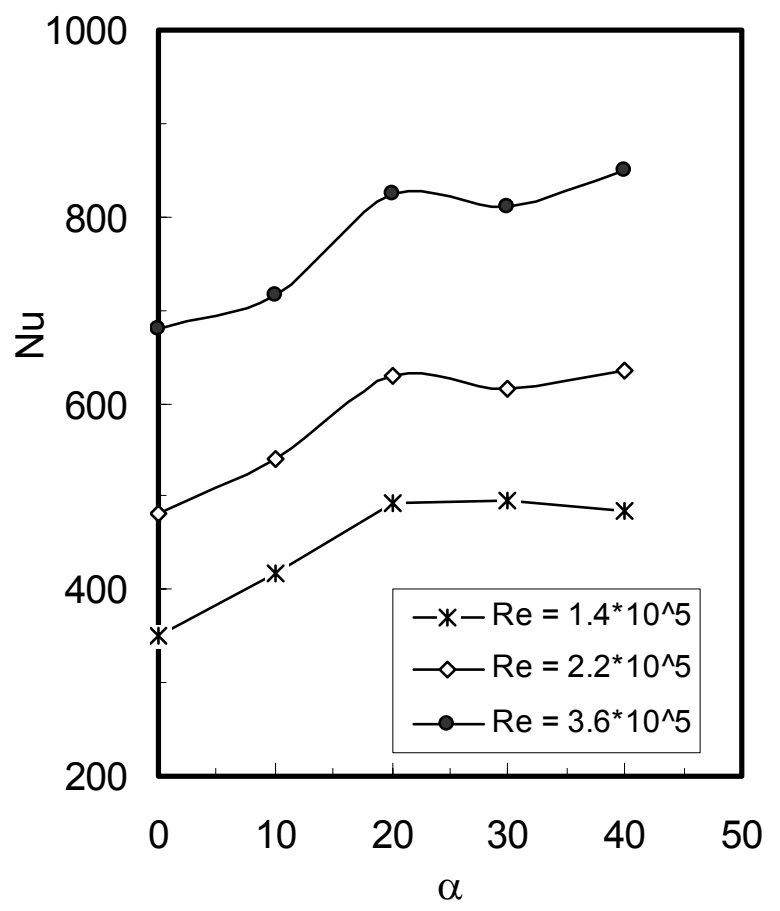

Fig. (9) Variation of Nusselt number with Reynolds number at different heat fluxes

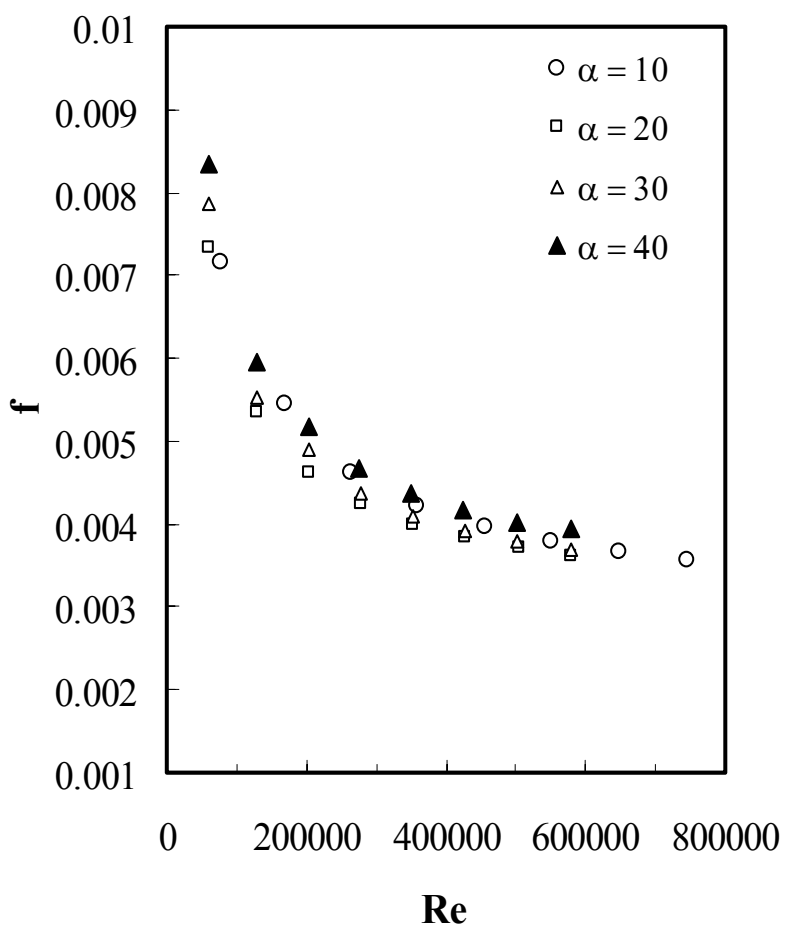

Fig. (8) friction factor vs. Reynolds number for different angles of attack

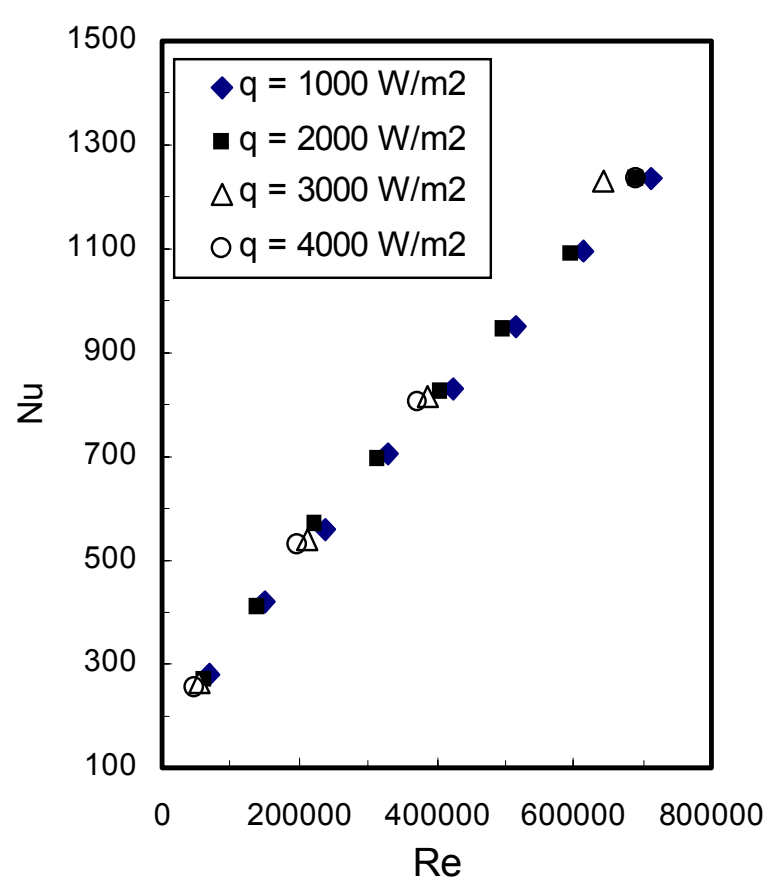

Fig. (10) Effect of heat flux on Nusselt number at $\alpha=30^{\circ}$ 


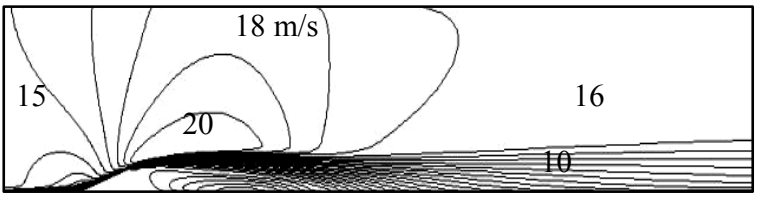

Fig. (11a) Velocity contours at $\alpha=20^{\circ}$

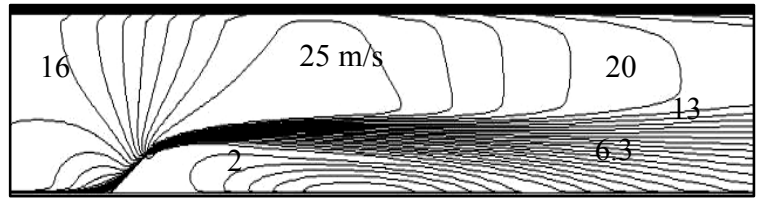

Fig. (11b) Velocity contours at $\alpha=40^{\circ}$

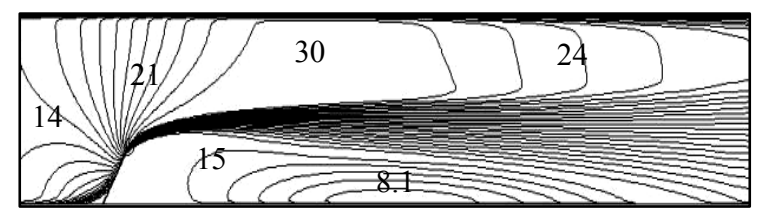

Fig. (11c) Velocity contours at $\alpha=60^{\circ}$



Fig. (11d) Velocity contours at $\alpha=80^{\circ}$



Fig. (12a) Pressure contours at $\alpha=20^{\circ}$

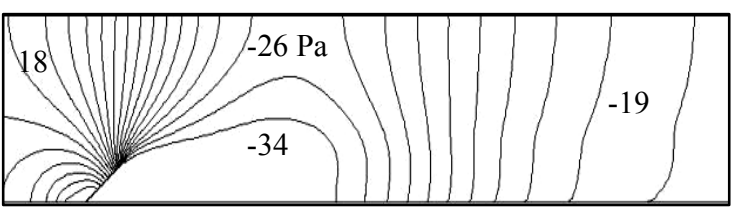

Fig. (12b) Pressure contours at $\alpha=40^{\circ}$



Fig. (12c) Pressure contours at $\alpha=60^{\circ}$



Fig. (12d) Pressure contours at $\alpha=80^{\circ}$ 


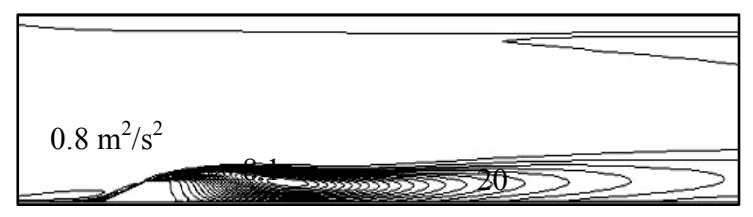

Fig. (13-a) Turbulent kinetic energy for $\alpha=0^{\circ}$

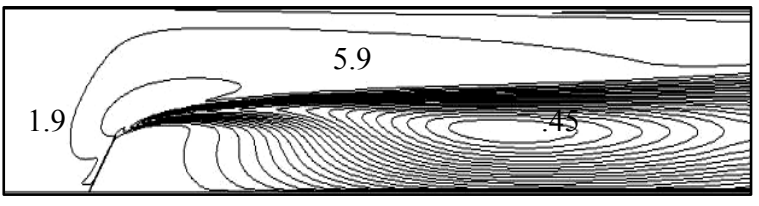

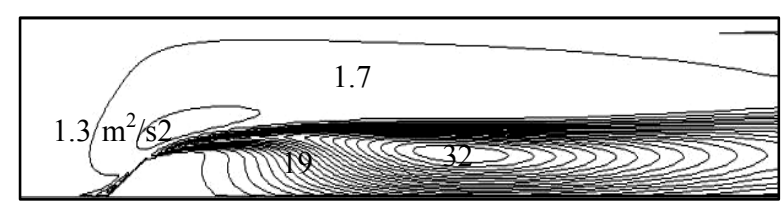

Fig. (13-b) Turbulent kinetic energy for $\alpha=20^{\circ}$

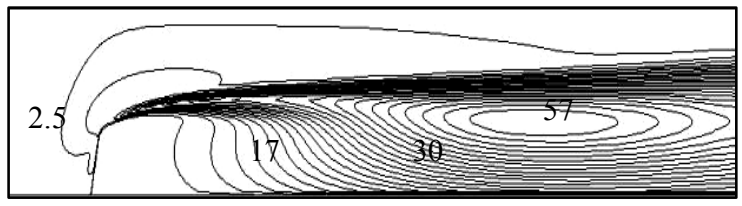

Fig. (13-c) Turbulent kinetic energy for $\alpha=60^{\circ}$ Fig. (13-d) Turbulent kinetic energy for $\alpha=80^{\circ}$ 